\title{
CFD Analysis of Splayed Pin Fin Heat Sink using Advanced Composite materials
}

\author{
I.Lakshmi Anusha ${ }^{\dot{A}^{*}}$, S.Murali $^{\dot{A}}$, P.Srinivas Rao ${ }^{\dot{\mathrm{B}}}$, P. Padmavathi ${ }^{\dot{\mathrm{C}}}$ \\ ${ }^{\dot{A}}$ Department of Mechanical Engineering, JPNCE,Mahabubnagar. \\ ${ }^{\dot{B}}$ Department of Aeronautical Engineering, Vardhaman College of Engineering, Shamshabad,Hyderabad and GEWS Technical Foundations, \\ Hyderabad, India. \\ ${ }^{\dot{C}}$ Department of Mechanical Engineering, Vardhaman College of Engineering, Shamshabad, Hyderabad.
}

Accepted 10 January 2014, Available online 01 February 2014, Special Issue-2, (February 2014)

\begin{abstract}
Seamless advancements in the electronics industry lead to high heat fluxes from very limited thermal real estates. The removal of excessive heat from system components is essential to avoid damaging effects of burning or overheating .Therefore the enhancement of heat transfer is an important subject of thermal engineering .Extended surfaces (fins) are frequently used in heat exchanging devices for the purpose of increasing the heat transfer between a primary surface and the surrounding fluid. The effective thermal management plays a vital role in the design and operation of electronic equipment .To obtain higher performance from a heat sink, more surface area, less weight and lower cost are necessary. Thus, efforts to obtain more optimized design i.e Splayed pin fin heat sinks and advanced composite materials are needed to achieve high thermal performance. The present study involves a splayed pin fin heat sink with advanced materials (Polyphenylene Sulphide (PPS),Carbon Foam, Graphite Epoxy) to ensure a reliable converter to extract these heat losses to limit temperature increases in the semiconductor device that would jeopardize reliability and performance, specifically keeping the device from exceeding its maximum operating temperature..It is observed that from the results the total weight of the system reduced drastically with the use of advanced materials at the same thermal performance.
\end{abstract}

Keywords: Splayed heat sink, Polyphenylene Sulphide, Carbon Foam, Graphite Epoxy.

\section{Introduction}

${ }^{1}$ Modern electronics thermal management face considerable challenges in the wake of component miniaturization which has led to higher demands on net heat flux dissipation. Various cooling mechanisms have been continuously employed to remove heat from heat sinks. The use of fins to enhance air cooling is the simplest and effective heat sink structure under the cost, space and weight constraints. Heat sinks are the most common thermal management to improve the thermal control of electronic components assemblies and modules. One of the more powerful cooling technologies that have emerged in recent years is the pin fin technology. Pin fin heat sinks for surface mount devices are available in a variety of configuration, sizes and materials. Splayed pin fin heat sinks are relatively new derivatives of the standard pin fin heat sink. Unlike standard pin fin heat sinks, which contain an array of vertically oriented pins, splayed pin fins features pins that gradually bend outward. Curving the pins in this way increases the spacing between the pins and allows surrounding air streams to enter and exit the pin array more efficiently without sacrificing surface area.

While, PPS, carbon foam, copper graphite epoxy is the current material of choice for heat sinks, the availability raises the possibility of lighter, more energy efficient,

*Corresponding author: I.Lakshmi Anusha

DOI: http://dx.doi.org/10.14741/ijcet/spl.2.2014.92 moldable plastic heat sinks with thermal performance in the range needed for commercial applications. The major advantage of these three heat sinks over all copper, aluminum and hybrid models is their lighter weight. So, depending on the size of the heat sink, composite materials may be up to $50 \%$ lighter than all-copper heat sinks of the same size.

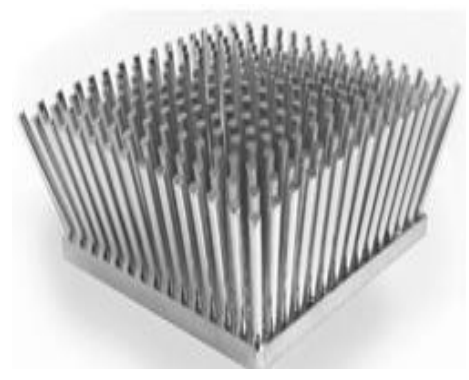

Fig.1. Splayed pin fin heat sink

\section{State of the art}

Wirtz et al1. reported experimental results on the thermal performance of model pin-fin fan-sink assemblies. They used cylindrical, square, and Diamondshaped cross-sectional pin-fins and found that cylindrical pin-fins give the best overall fan-sink performance. 
Furthermore, the overall heat-sink thermal resistance decreases with an increase in either pressure rise or fan power and fin height.

Jonson and Bjorn2 performed experiments to compare the thermal performance of heat sinks with different fin designs including straight fins and pin fins with circular, quadratic, and elliptical cross sections. They evaluated the thermal performance by comparing the thermal resistance of the heat sinks at equal average velocity and equal pressure drop. They recommended elliptical pin-fin heat sinks at high velocities and circular pin-fin heat sinks at midrange velocities. The steady-state thermal and air-flow resistance performances of horizontally based pin-fin assemblies were investigated experimentally by Tahat et al3 .They studied the effects of varying geometrical configurations of the pin-fins and found the optimal Pin fin separation in both stream wise and span wise directions to achieve maximum heat transfer rate.Jung and Maveety4 performed numerical experiments to investigate the turbulent fluid flowand heat transfer from three pin-fin heat sink geometries over the ReD range from 7800 to 19,700 with air impingement cooling. They used a standard k- $\varepsilon$ turbulence model to predict the Reynolds stresses. They found that the maximum heat transfer dissipated from a heat sink was obtained under turbulent flow conditions. Behnia et al5 compared numerically the heat transfer performance of various commonly used fin geometries (circular, square, rectangular, and elliptical).They fixed the fin crosssectional area per unit base area, the wetted surface area per unit base area, and the flow passage area for all geometries. They found that circular pin fins outperform square pin fins and elliptical fins outperform plate fins. They also found that elliptical fins work best at lower values of pressure drop and pumping work whereas round pin fins offer highest performance at higher values .Agnihothra Sharma6 compared CFD analysis of Splayed pin fin heat sinks for Aluminium, Copper and Hybrid materials. Based on the results he concluded that in the sense of junction temperature splayed pin fins are efficient. It is also found that Hybrid pin fin heat sinks have better performance than aluminium and copper pin fin heat sinks.

\section{Model analysis}

The modeling of pin fin heat sinks is made by GAMBIT 2.4.6 software.This analysis is based on the following assumptions:

1) The fins are with adiabatic tip.

2) The fluid, air is assumed to be incompressible throughout the process.

3) The airflow is normal to the fins.

4) Air properties are taken at film temperature.

5) The flow is steady, laminar and two dimensional.

6) There are no heat sources within the fin itself.

7) The radiation heat transfer is negligible.

8) The temperature at the base of the fin is uniform.

9) The heat flow in the fin and its temperatures remain constant with time.
10) The fin material is homogeneous and isotropic.

\section{Geometry}

Heat sinks, used in electronic devices, usually consist of arrays of pin-fins arranged in an in-line manner as shown in Fig 2. The pins are attached to a common base and the geometry of the array is determined by the pin dimensions, number of pins and pin arrangement.

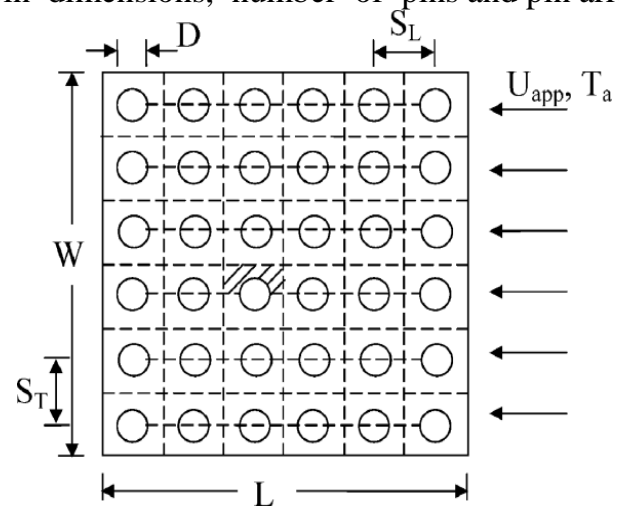

Fig 2: Schematic of in-line pin-fin heat sink.

Table 1 Dimensions used to determine performance of heat sinks

\begin{tabular}{|l|l|}
\hline Quantity & Dimension \\
\hline Footprint $(\mathrm{mm} 2)$ & $52 \times 52$ \\
\hline Base plate thickness $(\mathrm{mm})$ & 3 \\
\hline Overall height of fin $(\mathrm{mm})$ & 30 \\
\hline Approach velocity $(\mathrm{m} / \mathrm{s})$ & 3 \\
\hline $\begin{array}{l}\text { Thermal conductivity of solid } \\
\text { PPS }(\mathrm{W} / \mathrm{m} \cdot \mathrm{K})\end{array}$ & 20 \\
\hline $\begin{array}{l}\text { Thermal conductivity of solid } \\
\text { Carbon Foam }(\mathrm{W} / \mathrm{m} \cdot \mathrm{K})\end{array}$ & 120 \\
\hline $\begin{array}{l}\text { Thermal conductivity of solid } \\
\text { Graphite Epoxy }(\mathrm{W} / \mathrm{m} \cdot \mathrm{K})\end{array}$ & 370 \\
\hline Thermal conductivity of air $(\mathrm{W} / \mathrm{m} \cdot \mathrm{K})$ & 0.0284 \\
\hline Density of air $(\mathrm{kg} / \mathrm{m} 3)$ & 1.086 \\
\hline Specific heat of air $(\mathrm{J} / \mathrm{kg} \cdot \mathrm{K})$ & 1007 \\
\hline Kinematic viscosity $(\mathrm{m} 2 / \mathrm{s})$ & $18.15 \times 10-6$ \\
\hline Absolute viscosity $(\mathrm{Ns} / \mathrm{m} 2)$ & $19.70 \times 10-6$ \\
\hline Prandtl number $($ Air $)$ & 0.6976 \\
\hline Heat load $(\mathrm{W})$ & 130 \\
\hline Ambient temperature $(\mathrm{K})$ & 297 \\
\hline Base plate temperature $(\mathrm{K})$ & 353 \\
\hline
\end{tabular}

\section{Calculations}

To form an appropriate model for calculations, the following assumptions are made.

The contact resistance between the heat sink and processor would be negligible when using a high quality thermal paste.

The average temperature of the air flowing through the heat sink would be $325 \mathrm{~K}$, and used the values of material properties at $325 \mathrm{~K}$.

The Intel, core $\mathrm{i} 7-970$ processor is selected as heat source of $130 \mathrm{~W}$, to evaluate the pin fin heat sink performance. 
Reynolds's number $(\operatorname{ReL})=(\rho \mathrm{v} L) / \mu[\mathbf{1}]$

$\mathrm{Nu}=0.332$ ReL Pr [2]

$\mathrm{Nu}=\mathrm{h} 1 \mathrm{~L} / \mathrm{k}[3]$

$\mathrm{h} 1=\mathrm{Nu} \mathrm{k} / \mathrm{L}[4]$

$\mathrm{Vmax}=[\mathrm{ST} /(\mathrm{ST}-\mathrm{D})]$ Uapp [5]

$\operatorname{ReDmax}=\rho \operatorname{vmax} \mathrm{D}[\mathbf{6}]$

$\mathrm{Nu}=\mathrm{C}(\operatorname{ReDmax}) \mathrm{n}[7]$

$\mathrm{Nu}=\mathrm{h} 2 \mathrm{D} / \mathrm{k}[\mathbf{8}]$

$\mathrm{h} 2=\mathrm{Nu} k / \mathrm{D}[\mathbf{9}]$

\section{CFD simulation approach}

The ANSYS FLUENT 12.1 CFD code was used for the simulations. The simulation procedure was started with pre-processing. The computational mesh was generated using tetrahedral elements. In order to accurately resolve the solution fields in the high gradient regions, the grid was stretched. The discretization scheme was first order upwind scheme. A SIMPLE algorithm was used. For the simulations presented here, depending on the geometry used, fine mesh of up to $3,33,998$ elements were used. The flow field and heat transfer were determined by iteratively solving the governing momentum and energy equations. The under-relaxation factors were first set at low values to stabilize the calculation process, and were increased to speed up the convergence.

The normalized residuals were set at 10-4 for velocity components and at 10-7 for energy equation, which proved to be adequate.

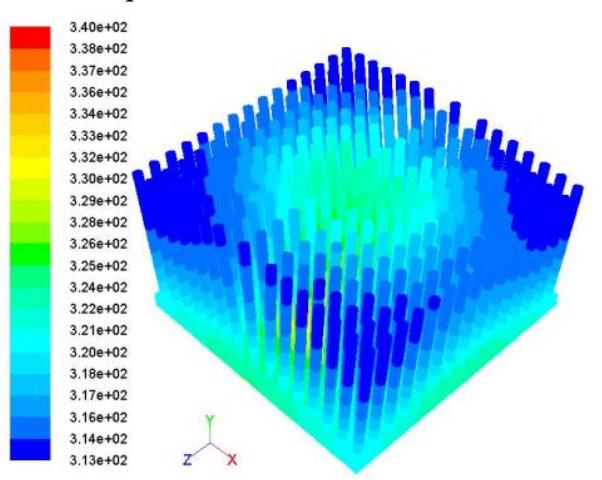

MWYS

Contours of Static Temperature (k)

Sep 23, 2013
ANSYS FLUENT 12.1 (3d, dp, pbns, ske)

Fig 3:Temperature Contours of Splayed PPS Pin Fin Heat sink with $3 \mathrm{~m} / \mathrm{s}$ velocity
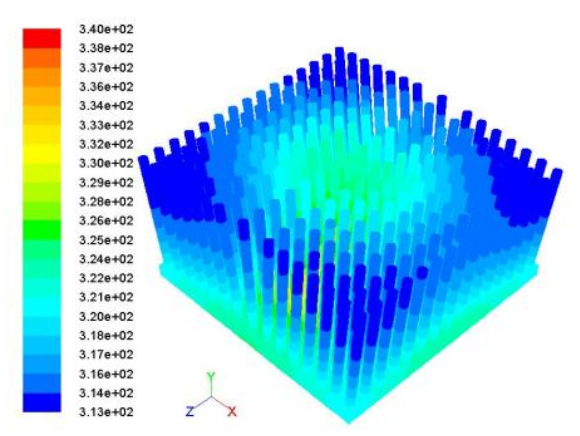

MSYS

Contours of Static Temperature $(\mathrm{k})$

Sep 26,2013
ANSYS FLUENT 12.1 (3d, dp, pbns, ske)

Fig 4:Temperature Contours of Splayed Carbon foam Pin Fin Heat sink with $3 \mathrm{~m} / \mathrm{s}$ velocity

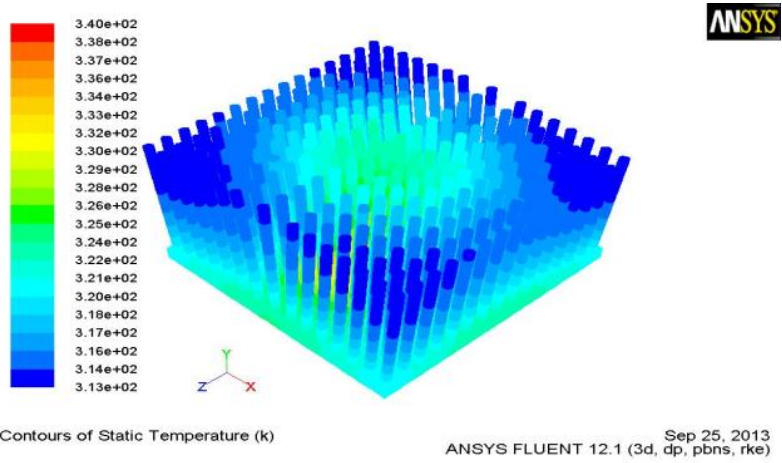

Fig 5:Temperature Contours of Splayed graphite epoxy Pin Fin Heat sink with $3 \mathrm{~m} / \mathrm{s}$ velocity.

\section{7 .Results \& Discussion}

From the table it is clear that composite materials pin fin heat sinks exhibits similar characteristics of aluminium, copper and hybrid pin fins. It is clear analysis that splayed composite material pin fin heat sinks enhances the heat transfer, when compared to the splayed hybrid pin fin heat sink.

\begin{tabular}{|l|l|}
\hline Splayed Heat Sink & Junction Temperature \\
\hline $\mathrm{Al}$ & 339 \\
\hline $\mathrm{Cu}$ & 327 \\
\hline Hybrid & 324 \\
\hline $\mathrm{PPS}$ & 320 \\
\hline Carbon Foam & 324 \\
\hline Graphite Epoxy & 325 \\
\hline
\end{tabular}

\section{Conclusions}

In the present paper CFD analysis of Splayed pin fin heat sinks for electronics cooling is investigated. Based on the results obtained it can be concluded that in the sense of junction temperature splayed pin fins are efficient .It is also found that total weight of the system may be reduced drastically with the use of advanced materials relative to most commonly used heat sink materials at the same thermal performance.

\section{References}

Wirtz, R. A., Sohal, R., and Wang, H., Thermal Performance of Pin-Fin Fan-Sink Assemblies Journal of Electronic Packaging, Vol. 119, March 1997, pp. 26-31. no.6, pp. 401-410.

Jonsson, H., and Bjorn, P.,Experimental Comparison of Different Heat Sink Designs for Cooling of Electronics, American Society of Mechanical Engineers, Heat Transfer Division, HTD, Vol. 329, No. 7, Association of Mechanical Engineers, New York, 1996, pp. 27-34

Tahat, M. A., Babus'Haq, R. F., and Probert, S. D.,Forced Steady-State Convections from Pin Fin Arrays, Applied Energy, Vol. 48, No. 4, 1994, pp. 335-351.

Jung, H. H., and Maveety, J. G., Pin Fin Heat Sink Modeling and Characterization,Sixteenth IEEE Semi-Therm Symposium, IEEE Publications, Piscataway, NJ, March 2000, pp. 260-265

Behnia, M., Copeland, D., and Soodphadakee, D., 1998, A Comparison of Heat Sink Geometries for Laminar Forced Convection,Proceedings of The Sixth Intersociety Conference on Thermal and Thermomechanical Phenomena in Electronic Systems, Seattle, Washington, USA, May 27-30, pp. 310-315

Agnihothra Sarma O et. al. CFD Analysis of Splayed Pin Fin Heat Sink for Electronic Cooling International Journal of Engineering Research and Technology Vol. 1 (10), 2012, ISSN $2278-0181$

Kodandaraman, C.P., Heat and Mass Transfer Data Book. http://www.ecnmag.com/articles/2010/01/nextgenerationpin-fin-heat-sinksprovide-superior cooling power 